\title{
Chlamydial immunofluorescence serology in anterior uveitis
}

\author{
LEENA MATTILA, ${ }^{2}$ LOTTA SALMINEN,${ }^{1}$ AND PERTTI TERHO ${ }^{2}$ \\ From the 'Department of Ophthalmology, Turku University Central Hospital, Turku, and the \\ ${ }^{2}$ Department of Virology, University of Turku, Turku, Finland
}

SUMMARY Chlamydial immunofluorescence (IF) serology was determined in 118 patients with acute anterior uveitis (AAU), half of whom had anti-chlamydia antibodies. Men and women were equally affected. The chlamydial IF antibody titre was generally $1 / 16-64$, but a few higher values were also measured. The age distribution, ocular pathology, and duration of AAU were identical in the chlamydial seropositive and seronegative patient groups. In the seropositive group there were 3 men with Reiter's syndrome. The prevalence of anti-chlamydia antibodies $(50 \%)$ was higher than in other patients studied in the same laboratory. Further population studies are in progress to see whether our AAU patients represent an accumulation of chlamydial-positive persons.

Infections due to Chlamydia trachomatis serotypes D to $\mathrm{K}$ are sexually transmitted and are increasingly common among persons aged $20-40$ years. In the same age group the frequency of acute anterior uveitis (AAU) is greatest. ${ }^{1}$

Specific micro-organisms, such as klebsiella, yersinia, and salmonella, are thought to be involved in the development of AAU. ${ }^{2-5}$ Chlamydia has also been linked to AAU, which may occasionally develop either during the acute course of a chlamydial conjunctivitis ${ }^{6-8}$ or months after a conjunctival infection. ${ }^{67}$ Intraocular inflammation may present as the ocular component of Reiter's syndrome, of which chlamydia may be one principle aetiological factor. $^{7910}$

This study reports the serological findings, as measured by an indirect immunofluorescence test (IF), and conjunctival isolations of $C$. trachomatis in patients with AAU. Part of the study has been previously published. ${ }^{11}$

\section{Patients and methods}

The subjects of the study were 118 patients with AAU treated at the Outpatient Clinic of the Department of Ophthalmology, Turku University Central Hospital, from January 1978 to December 1979. Patients who

Correspondence to Dr Lotta Salminen, MD, Department of Ophthalmology, Turku University Central Hospital, SF-20520 Turku 52, Finland. had AAU due to ocular trauma or concomitant conjunctival or corneal diseases were excluded from the study. Only one patient had a history of genital chlamydial infection.

In biomicroscopic ocular examination the quantity and the quality of keratic precipitates, aqueous flare and cells, and vitreous inflammatory signs were recorded. Applanation tonometry and ophthalmoscopy were performed in all cases.

The following laboratory tests were carried out for each patient: erythrocyte sedimentation rate (ESR), peripheral blood leucocyte count, the latex and Waaler-Rose test for rheumatoid factor, antistreptolysin $\mathrm{O}$, antistaphylolysin, antiyersinia antibody and antichlamydia antibody determinations, conjunctival swabbings from both eyes for chlamydia isolation, and $x$-ray examination of the chest, sinuses, and lumbosacral spine. In some cases serological tests for toxoplasma, rubella, Mycoplasma pneumoniae, and antinuclear antibodies, and the isolation of gonorrhococci from the urethra were carried out. The hospital records were reviewed with attention to the possible recurrences of AAU and associated diseases.

Antichlamydia antibody determinations were carried out by immunofluorescence test. The technique has been described previously. ${ }^{12}$ Briefly, irradiated McCoy cells on a slide were infected with a $0.5 \mathrm{ml}$ of $C$. trachomatis $\left(\mathrm{L}_{2}\right)$ inoculum to produce approximately 5000 inclusions. The slide was divided with nail polish into 32 squares, on which serial dilutions of serum were pipetted. After incubation 


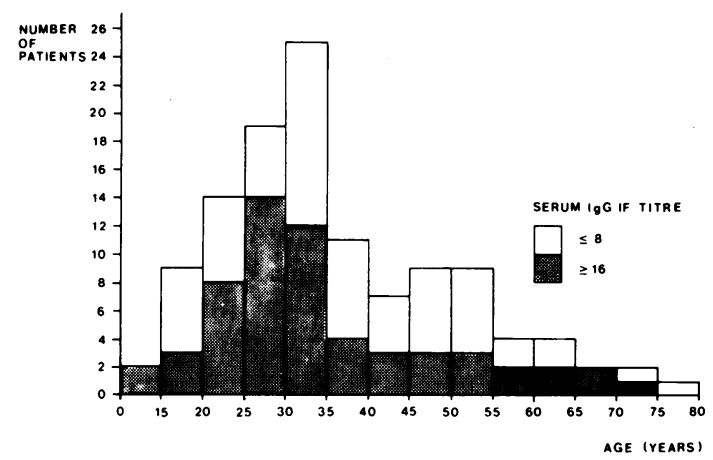

Fig. 1 Age distribution of chlamydial seropositive (titre $\geq 1 / 16$ ) and seronegative (titre $\leq 1 / 8) A A U$ patients.

and washing a fluorescein isothiocyanate (FITC) conjugated pretitrated working dilution (usually $1 / 40$ ) of rabbit antihuman IgG (Dako, Denmark) was added and again incubated in a moist chamber. After washing and drying the slide a cover glass was mounted with Depex and standard FITC microscopy was performed. The serum titre was recorded as the highest dilution that showed clear inclusion body fluorescence. The dilution of $1 / 16$ was considered to be reactivity of the test.

The isolation technique for $C$. trachomatis has been described in detail previously. ${ }^{13}$ Briefly, irradiated McCoy cells grown on a cover glass in flat-bottomed tubes were infected by centrifugation $(15000 \mathrm{~g}$ for 1 hour at $35^{\circ} \mathrm{C}$ ). After incubation for 72 hours in $\mathrm{CO}_{2}$ at $35^{\circ} \mathrm{C}$ the cells were stained with iodine. Chlamydial inclusions were identified by light microscopy.

\section{Results}

The isolation of $C$. trachomatis from bilateral conjunctival swabbings was negative in all patients. Out of the 118 AAU patients $59(50 \%)$ had antibody titres $\geq 1 / 16$ against chlamydia.

The age distribution in the seropositive and seronegative AAU patient groups was identical (Fig. 1). The mean age of chlamydial seropositive patients was 36 years (range 5-73) and that of chlamydial seronegative AAU patients 39 years (range 16-77 years). Both sexes were equally distributed among seropositive and seronegative groups. There were 31 $(52.5 \%)$ men and $28(47.5 \%)$ women in the seropositive and $35(59 \cdot 3 \%)$ and $24(40.7 \%)$ in seronegative groups respectively.

The chlamydial IF antibody titres in the 59 chlamydial seropositive AAU patients were generally 1/16-64, but higher titres were also measured. The distribution of antichlamydia antibody titres was identical in both sexes and in different age groups.
CLINICAL PICTURES AND FEATURES OF AAU In the 59 chlamydial seropositive and seronegative AAU patients the ocular inflammation was recurrent in 17 and 14 patients respectively. The relapse was in the same eye in 8 seropositive and in 2 seronegative patients. During the follow-up period AAU was bilateral in 4 and 5 seropositive and seronegative patients, respectively.

The ocular pathology in patients who had antichlamydia antibodies did not differ from that in the seronegative cases of AAU. There was no relationship between the intensity of the uveitis and the height of the antichlamydia antibodies. Keratic precipitates (never mutton-fat) flare and cells in the anterior chamber were seen to the same extent in both groups. One chlamydial seropositive patient had hypopyon and one hyphaema. Fibrin in the anterior chamber was present at the beginning of AAU in 6 seropositive and in 13 seronegative cases. Posterior synechiae were noticed during the disease in 18 seropositive and 22 seronegative patients, and the pupil remained irregular in 7 and 10 cases respectively.

In the anterior vitreous there were cells in 17 seropositive and 7 seronegative cases. In both groups there were 3 eyes with macular oedema, and one seropositive patient had papillary oedema. In 5 eyes in both groups the intraocular pressure was $\geq 21$ $\mathrm{mmHg}$ and in 12 eyes in the seropositive AAU group and in 10 eyes in the seronegatives $\leq 8 \mathrm{mmHg}$. The duration of the uveitis was almost same in both groups. The mean duration was 6.6 weeks in the seropositive AAU and 5.7 weeks in the seronegative AAU group.

\section{GENERAL PATIENT STATUS}

The positive laboratory and $x$-ray findings other than chlamydial are summarised in Table 1. $X$-ray examination confirmed 5 cases in the chlamydial

Table 1 Number of positive laboratory and $x$-ray examinations in the chlamydial seronegative and seropositive AAU patient groups

\begin{tabular}{lcc}
\hline $\begin{array}{l}\text { Laboratory test and } x \text {-ray } \\
\text { examinations }\end{array}$ & \multicolumn{2}{c}{ Number of patients } \\
\cline { 2 - 3 } & Serum IgG IFAT titre \\
\cline { 2 - 3 } & $\leq 1 / 8$ & $\geq 1 / 16$ \\
\hline ESR $\geq 20$ & 17 & 10 \\
Leucocytes $\geq 10 \times 10^{9} / 1$ & 5 & 4 \\
Latex +-+++ & 1 & 1 \\
Waaler-Rose $\geq 64$ & 2 & 4 \\
AST titre $\geq 350$ & 11 & 11 \\
Antiyersinia antibodies & 4 & 6 \\
$X$-ray: chest & 1 & 1 \\
$\quad$ sinuses & 4 & 2 \\
$\quad$ lumbosacral spine & 8 & 7 \\
\hline
\end{tabular}


seropositive and 6 cases in the chlamydial seronegative AAU group with sacroilitis and 2 cases in both groups with other abnormalities in the lumbosacral spine. All the positive $x$-ray findings in sinuses and chest were classified as inflammatory by the roentgenologist. In both groups there was one patient with psoriasis vulgaris. One patient with antichlamydia antibodies had erythema nodosum 3 months before the onset of AAU.

In the seropositive group there were 3 men with Reiter's syndrome. They all had fresh arthritis during the AAU and had had symptoms of urethritis, prostatitis, and epididymitis-namely, discharge with and without dysuria-for about 6 months. Two of them had had gonorrhoea and one of them keratitis twice. During the urethritis the patients were treated with systemic tetracycline and/or erythromycin. There was no urethral chlamydial isolation. During the AAU all diagnostic tests except that for chlamydial blood serology were negative. Two of them had antichlamydia antibody titres of $1 / 512$ and the third 1/256. Before the onset of ocular inflammation from one patient with Reiter's syndrome an antichlamydia antibody titre of $1 / 512$ was measured from the synovial fluid of the knee.

\section{OCULAR TREATMENT}

All AAU cases were treated with topically applied cycloplegics and corticosteroids. In 6 of the seropositive patients and 5 of the seronegative the AAU was so severe that systemic corticosteroid treatment was given.

\section{SYSTEMIC TREATMENT}

Five patients with high antichlamydia antibodies were treated with systemic tetracycline. Three of them had Reiter's syndrome. In the chlamydial seropositive and seronegative groups one patient had systemic tetracycline therapy for acute yersiniosis. The indication for systemic tetracycline therapy in 3 seronegative patients was inflammatory infiltrates in the chest and sinuses and cementoperiostitis. In both groups 2 patients who had elevated AST titres were treated with systemic penicillin. One child with antichlamydia antibodies and with sinuitis was treated with systemic erythromycin and the one with pulmonary infiltrates with amoxicillin. All the patients with an inflammatory process recovered well.

\section{Discussion}

In our study AAU observed in patients with antichlamydia antibodies differed neither clinically nor epidemiologically from AAU observed in patients with no antichlamydia antibodies. In both patient groups other positive laboratory tests and positive $x$-ray examinations for an aetiological diagnosis of AAU were equally represented. Patients with antichlamydia antibodies included 3 men with Reiter's syndrome, which was the only clinical difference observed between the chlamydial positive and negative patient groups.

AAU patients with and without antichlamydia antibodies had in 6 and in 4 cases, respectively, concomitantly raised levels of anti-yersinia antibodies in their sera. The appearance of antibodies against both yersinia and chlamydia indicates double infection in these patients. ${ }^{4}$

In our AAU patient material the prevalence of antichlamydia antibodies was high $(50 \%)$. The prevalence of antichlamydial antibodies in adults (London blood donors) has been reported to be $17 \%$ in women and $26 \%$ in men. ${ }^{14}$ Among pregnant Swedish women a serological study of blood samples has shown every second woman to have antichlamydia antibodies with a titre $\geq 1 / 32 .{ }^{15}$ In our patients, in Finnish army recruits, ${ }^{16}$ and in Finnish women attending maternal care units (P. Terho, personal communication) the percentage of chlamydial positive persons has been notably smaller, $28 \%$ and $20 \%$ respectively. The antibody determinations in our studies was made by the same laboratory in all cases. Further population studies are in progress to determine whether our AAU material represents an accumulation of chlamydial positive persons.

In experimental animals and in man chlamydial organisms have been an aetiological factor for intraocular inflammation. In rabbits intracameral inoculation of chlamydia isolated from synovial membrane of a patient with Reiter's syndrome induced iritis. ${ }^{17}$ The same isolate injected into the knees of rabbits induced chronic arthritis, which was later complicated by iritis. ${ }^{18}$

Human chlamydial conjunctivitis has been complicated by AAU. ${ }^{6-8}$ In some cases the uveitis developed in the course of conjunctival reinfection ${ }^{6}$ or several months after the conjunctival infection had subsided. ${ }^{7}$ In Reiter's syndrome chlamydia was isolated from the patients' conjunctiva, and the patients had significantly elevated antichlamydia antibodies in their sera..$^{79}$ In our material all the chlamydia isolation attempts from the conjunctiva were negative. This excludes the possibility of conjunctival reinfection by chlamydia as a trigger mechanism for AAU. Patients with conjunctival or corneal diseases were excluded from our series; none of the AAU cases was directly caused by chlamydial conjunctivitis.

In recent years there has been growing evidence for the possible role of Gram-negative organisms in the generation of AAU in genetically predisposed persons. $^{245}$ This role is connected with structural 
similarities and cross-reactivity of bacteria with tissue antigens of the eye. ${ }^{1920}$ Chlamydia have structural similarities with Gram-negative bacteria, and they might also share common immunobiological functions. ${ }^{21}$

If chlamydia can be proved to have immunological properties similar to those of, for example klebsiella, they might be one alternative in the pathogenesis of postinfectious complications leading, by some unknown trigger mechanism, to inflammation in the eye. Further experimental and population studies are needed to evaluate this hypothesis.

\section{References}

1 Schlaegel Jr TF. General factors in uveitis. In: Duane TD, ed. Clinical Ophthalmology. External Diseases. The Uvea. Philadelphia: Harper and Row, 1981: 4: 39:1-3.

2 Willshaw HE, Eastmond CJ. Role of environmental factors in uveitis. Trans Ophthalmol Soc UK 1979; 99: 160-2.

3 Saari KM, Laitinen O, Leirisalo M, Saari R. Ocular inflammation associated with yersinia infection. Am J Ophthalmol 1980; 89: 84-95.

4 Mattila L, Granfors K. Toivanen A. Acute anterior uveitis after yersinia infection. Br J Ophthalmol 1982; 66: 209-12.

5 Saari KM, Vilppula A, Lassus A, Leirisalo M, Saari R. Ocular inflammation in Reiter's diseases after salmonella enteritis. Am J Ophthalmol 1980; 90: 63-8.

6 Dawson C, Wood TR, Rose L, Hanna L. Experimental inclusion conjunctivitis in man III. Keratitis and other complications. Arch Ophthalmol 1967; 78: 341-9.

7 Dawson CR, Schachter J, Ostler HB, Gilbert RM, Smith DE, Engleman EP. Inclusion conjunctivitis and Reiter's syndrome in a married couple. Chlamydia infections in a series of both diseases. Arch Ophthalmol 1970; 83: 300-6.

8 Verin PH, Gendre PH, Vildy A, Cales M, Kani M, Bapte J-B.
Trachoma and inclusion conjunctivitis similarities and differences. Rev Int Trach Pathol Ocul Trop Subtrop 1980; 57: 19-51.

9 Schachter J, Dawson CR. Human Chlamydial Infections. Littleton: PSG, 1978: 141-52.

10 Lassus A, Kousa A. Reiter's disease. In: Harris JRW, ed. Recent Advances in Sexually Transmitted Diseases. Edinburgh, London, Melbourne, New York: Churchill-Livingstone, 1981 187-99.

11 Salminen L, Mattila L, Terho P. Chlamydial blood serology in patients with anterior uveitis. In: Trevor-Roper PD, ed. Royal Society of Medicine Series. VIth Congress of the European Society of Ophthalmology. London: Academic Press, 1981; 40: 493-4.

12 Saikku P, Paavonen J. Single-antigen immunofluorescence test for chlamydial antibodies. J Clin Microbiol 1978; 8: 119-22.

13 Terho P. Isolation techniques of Chlamydia trachomatis from patients with nonspecific urethritis. Dermatol Monatsschr 1978; 164: 515-20.

14 Darougar S, Forsey T, Brewerton DA, Rogers KL. Prevalence of antichlamydial antibody in London blood donors. BrJ Vener Dis 1980; 56: 404-7.

15 Persson K, Rönnerstam R, Svanberg L, Holmberg L. Maternal and infantile infection with chlamydia in a Swedish population. Acta Paediatr Scand 1981; 70: 101-5.

16 Terho P. Chlamydia trachomatis in male urethritis. A clinical, microbiological and serological study. Academic Dissertation. University of Turku, Finland, 1979.

17 Ostler HB, Schachter J, Dawson CR. Ocular infection of rabbits with a bedsonia isolated from a patient with Reiter's syndrome. Invest Ophthalmol Visual Sci 1970; 9: 256-62.

18 Smith DE, James PG, Schachter J, Engleman EP, Meyer KF Experimental bedsonial arthritis. Arthritis Rheum 1973; 16: 21-9.

19 Avakian H, Abuknesha R, Welsh J, Ebringer A. Uveitis, vitreous humour, and klebsiella. I. Binding studies with rabbit antisera. Br J Ophthalmol 1981; 65: 315-22.

20 Welsh J, Avakian H, Ebringer A. Uveitis, vitreous humour, and klebsiella. II. Cross-reactivity studies with radioimmunoassay. $\mathrm{Br}$ J Ophthalmol 1981; 65: 323-8.

21 Caldwell HD, Kromhaut J, Schachter J. Purification and partial characterization of the major outer membrane protein of Chlamydia trachomatis. Infect Immun 1981; 31: 1161-76. 